\section{EL TRABAJO INTELECTUAL EN EL ENTORNO DIGITAL: NUEVAS FORMAS DE ESCRITURA Y DE ERUDICIÓN}

\author{
José Luis González Quirós ${ }^{1-2}$ \\ Instituto de Filosofía, \\ Centro de Ciencias Humanas y Sociales del CSIC \\ C/ Albasanz, 26-28, 28037 Madrid, España \\ jlgg@ifs.csic.es,jlgonzalezquiros@gmail.com
}

\section{THE INTELECTUAL WORK ON THE DIGITAL ENVIRONMENT: NEW KINDS OF WRITING AND ERUDITION}

ABSTRACT: The digital environment constitutes a brand new scenario in which research, reading and writing will be developed in the future. Its nature, wildly different to that typical from the environment created by the printing press, will certainly modify the work methods of both authors and scientists, as well as our intellectual behaviour, and the way in which our ideas are argued. Writing and reading are human activities since immemorial times. This fact has led us to forget that they are an invention; they are technology, a simple one, but not something natural or spontaneous at all, as it is evident by the long time that is necessary to dedicate to their understanding in our education. The digital environment provides us with both a new office and a new market; though it still may be too early to see it, new forms of authorship, writing and digital erudition are being created.

KEY WORDS: Digital environment, writing, reading, erudition, descriptors, World III.
RESUMEN: El entorno digital constituye el nuevo escenario en que se ha de desarrollar la investigación, la lectura y la escritura en el futuro. Su naturaleza, profundamente distinta de la que es propia del entorno que se creó con la imprenta, modificará con toda seguridad las formas de trabajo de los autores y estudiosos, las prácticas intelectuales y la manera en la que se argumentan las distintas exposiciones. La escritura y la lectura son actividades humanas que, debido a su ejercicio ya inmemorial, nos han hecho olvidar su condición de invento, de tecnologías, simples pero nada naturales ni espontáneas, como lo prueba el hecho del mucho tiempo que hay que dedicarles en la educación. El entorno digital nos dota, a la vez, de un nuevo escritorio y de un nuevo mercado: aunque aún es pronto para verlo, se están creando nuevas formas de autoria, de escritura y de erudición digital.

PALABRAS CLAVE: Entorno digital, lectura, escritura, erudición, autoría, erudición, descriptores, Mundo III.

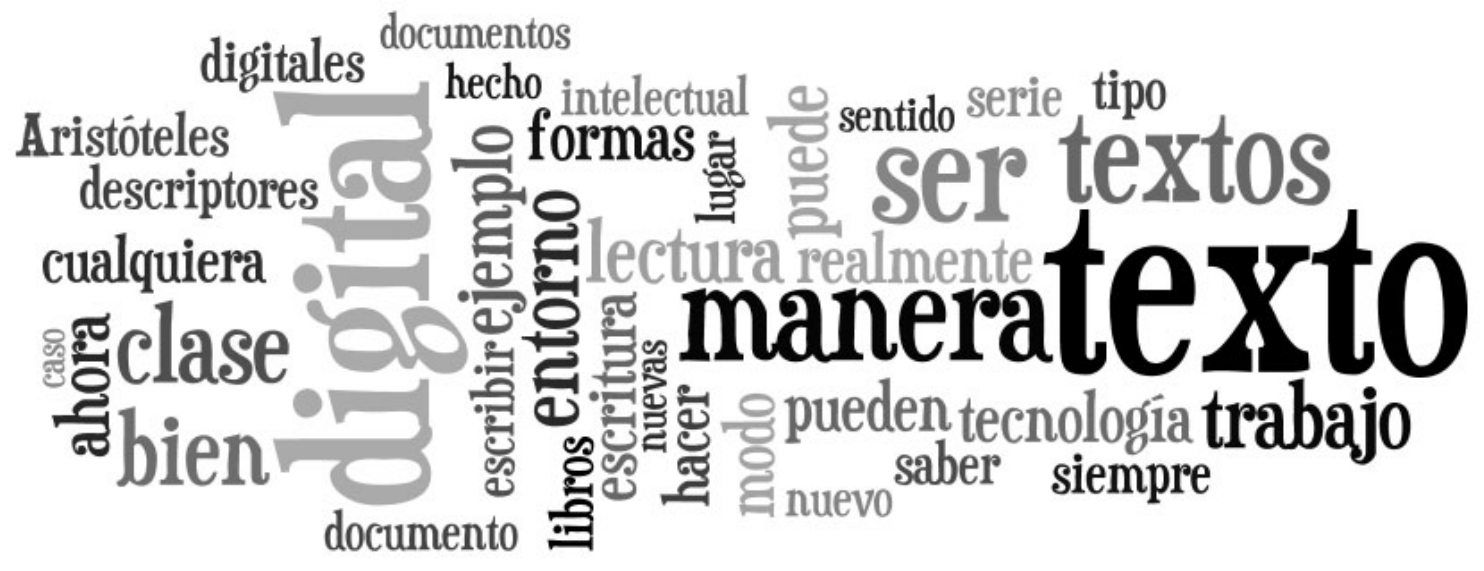


Aunque Aristóteles creía que el afán de saber es natural en todos los hombres supo darse cuenta de que, para dedicarse a investigar, se necesitaban una serie de condiciones, tanto de tipo intelectual como de tipo material. Como ejemplo de las primeras valga el examen que, como es bien sabido, dedicó a las opiniones de quienes le precedieron, al comienzo mismo de su Metafísica. Pero las necesidades que reconocía el gran filósofo griego no se referian únicamente a disponer de un saber del pasado. Nuestro pensador era bien consciente de que gozar de unas ciertas condiciones materiales resultaba imprescindible para poder dedicarse al saber, porque, por ejemplo, para hablar del pasado tenemos que tener tiempo, libertad, un lugar de trabajo adecuado, además de libros, memorias, relatos de lo que fue, de lo que pensaban y, por supuesto, tenemos que tener también las instituciones en las que se guardan, organizan y cuidan esos libros.

Aristóteles pudo ser tan riguroso interpretando las doctrinas de quienes le precedieron porque disponía ya de un mínimo de instrumentos materiales que se lo permitían. Aunque su manera de abordar esta cuestión constituia una novedad casi absoluta por su sistematismo, el hecho es que Aristóteles pudo ser original porque podia conocer bien lo que se había dicho antes que él sobre las cuestiones en que se interesaba. No hay que ser un gran historiador para caer inmediatamente en la cuenta de que las condiciones que le permitían el trabajo a Aristóteles nos las impedirian a la mayoría de nosotros y que, desde la biblioteca del monasterio medieval hasta nuestro puesto delante de un ordenador, las cosas han cambiado muy mucho. Es evidente, sin embargo, que tanto Aristóteles, como los monjes y los científicos de la época moderna han hecho algo muy similar a lo que hacemos cualquiera de nosotros cuando queremos investigar: nos retiramos del mundo común a un lugar solitario y tranquilo porque queremos aclararnos, porque tratamos de saber, de responder a una serie de preguntas que han variado mucho desde Aristóteles pero que siguen teniendo el mismo sentido. Para ello hemos trabajado en distintos campos y nos ponemos a estudiar, a repasar las notas que hemos tomado, a leer ciertos documentos, tras lo cual, y con un ritmo que no es nada fácil describir, nos ponemos a pensar y escribimos para dar a conocer nuestras invenciones y ocurrencias.

Cuando miramos atrás para ver cómo se desarrollaba el oficio intelectual, las analogías son, por tanto, tan impor- tantes como las diferencias. Lo que estamos diciendo no es sino una obviedad de trazo grueso de manera que no merecería mayor comentario si no fuese porque nos sirve para plantear la cuestión siguiente: ¿Cómo va a cambiar la forma en que desarrollamos el trabajo intelectual en el entorno digital? ¿Cuáles van a ser las nuevas formas de lectura, de escritura y de erudición? Estamos, en primer lugar, ante un cambio radical del entorno en el que se realiza cualquier clase de trabajo científico, intelectual o creativo. Me limitaré a señalar lo que me parece más innegable, la revolución en las dimensiones. Citaré el dato que me parece más revelador en este contexto, aunque se refiera a una situación que ya era abrumadora antes de la era digital: hacia mediados de la segunda mitad del pasado siglo, el matemático polaco Stanislaw Ulam (Ulam, 1976) hizo una estimación acerca del número de nuevos teoremas matemáticos que se publicaban cada año: la cifra, unos 200.000, le dejó a él mismo un tanto estupefacto.

Tanto en matemáticas como en cualquier otro tipo de disciplina, estamos antes uno de esos casos en que la magnitud de las cifras ha cambiado de manera rotunda el sentido del problema. Aristóteles necesitaba consultar las opiniones, a lo sumo, de unas decenas de personas, unas ideas que estaban suficientemente recogidas en un número realmente pequeño de documentos, de lo que hoy llamaríamos libros: nosotros, para poder hacer lo que Aristóteles hizo, nos enfrentamos a magnitudes inabarcables, a cientos de miles de documentos, una cifra que no cesa de crecer, por otra parte. Esto significa, entre otras cosas, que, sencillamente, no podemos hacer lo que hacía Aristóteles. $\mathrm{Ni}$ podemos conocer suficientemente bien el pasado que nos interesaría conocer ni podemos aprovechar toda la luz que podríamos sacar de él.

Cuando examinamos con cierto detenimiento los detalles de este problema, las cifras vuelven a ser realmente de pasmo, tanto si nos referimos a los artículos de revista científica que, aparentemente al menos, nadie lee porque nadie los cita, como si nos referimos a los miles de libros que tratan un tema y que nadie, absolutamente nadie consulta. Pongamos un ejemplo para hacer más expresivo lo que esto significa. Cualquiera de nosotros que quiera hacer un viaje entre, por ejemplo, Barcelona y Berlín, dispone de miles de planos de carretera, de cientos de guias que explican los enlaces ferroviarios a los que puede recurrir y de un buen montón de compañías aéreas que le ofrecerán toda 
clase de combinaciones para hacer ese viaje. Pensemos ahora en un extremeño del siglo XII que por alguna extraña razón hubiese oído hablar de Berlín y tuviese el insólito propósito de dirigirse a esa población (si es que en aquella época había algo con ese nombre). Tendría que atreverse a iniciar una aventura realmente arriesgada en la que las posibilidades de fracaso y de extravío serían enormes. Pues bien, en el mundo de la ciencia y del conocimiento en general, pese a lo mucho que sabemos y a pesar de los esfuerzos de unos y de otros, no se conservan con la debida seguridad los planos que es trivial encontrar en el mundo de los viajes. No olvido que, desde luego, hay muchísimas cosas que sabemos con un nivel plenamente satisfactorio de certidumbre, pero, sin embargo, son literalmente infinitas las cuestiones que ignoramos ( $y$, entre ellas, las que no somos conscientes de ignorar porque las encubrimos con una creencia inconsciente y equivocada), y no son menos las que están bien resueltas pero que prácticamente nadie sabe cómo se resuelven porque las soluciones están perdidas en cualquiera de esos millones de textos que han resultado involuntariamente estériles. La mayoría de la gente no es consciente de esta clase de abismos porque, muy cuerdamente, prefiere viajar por autopistas bien asfaltadas y señalizadas, pero cualquiera que se salga del camino más trillado, que investigue realmente, se enfrenta a una riesgosa aventura, puesto que es muy probable que haya planos pero es extraordinariamente fácil que no consiga encontrarlos: puede decirse que la misma abundancia nos procura un tipo peculiar de escasez.

La receta tradicional para corregir esta clase de malformaciones insistía en la autocontención y en el orden. Va para cien años que Ortega y Gasset $(1962,113)$ Ilamó la atención sobre esta clase de cuestiones afirmando que la obra de caridad más propia de nuestro tiempo era no publicar libros superfluos, aunque, justo es decirlo, no aclaró mucho la cuestión de cómo diferenciar los libros superfluos de los que no lo son. Desde la época en que hablaba Ortega hasta ahora la cosa se ha complicado bastante, entre otras cosas porque la rebelión de las masas no se ha quedado en lo que Ortega veía. Ahora, gracias a Internet y al desarrollo de lo que se ha llamado la Web 2.0, ha habido un crecimiento enorme del número de autores, del número de voces que dejan algún registro de su existencia y que hacen afirmaciones o negaciones sobre asuntos que la mayoría no estamos en condiciones de verificar. La atmósfera del saber se encuentra repleta de nuevas e incesantes fuentes de información que surgen por todas partes y los medios clásicos están empezando a hacerse conscientes de la clase de desplazamiento y de descentralización que todo esto está trayendo consigo.

Se ha dicho que vivimos en "el culto de lo amateur" (Keen, 2007), la eclosión del universo de opiniones de millones de personas que se asoman al escenario más concurrido para coparlo, de modo que los espacios privilegiados en que se podia pontificar, con mayor o menor fundamento sobre toda clase de cosas (editoriales de los periódicos serios, crítica profesional, lugares especialmente reconocidos como autoridad) parecen estar sucumbiendo ante el empuje de los blogs y las wikis. Por decirlo de algún modo, la Wikipedia, que casi ha retirado de la circulación a la prestigiosísima Encyclopædia Britannica, es, a muchos efectos, casi tan fiable como lo fue siempre aquella, aunque cualquiera que tratase de hacer un trabajo académicamente fiable haría bien en no dar por descontado lo que la Wikipedia dice porque, como es inevitable, abundan los errores en ella (según algunas estimaciones, contiene casi el doble de errores que la Encyclopædia Britannica). Lo asombroso es que la proliferación de lo que podríamos llamar mensajeros originales y/o espontáneos no acabe por provocar siempre un auténtico caos (Surowiecki, 2004). Para mencionar un ejemplo obvio de caos sobrevenido por la proliferación de opiniones (aunque también por la ausencia de pruebas decisivas y por lo extremado de la variación entre las posibles hipótesis), bastará con traer a colación un suceso bien conocido, la desaparición de una niña inglesa, Madeleine McCann, en una colonia de vacaciones del sur de Portugal, un caso en el que la prensa tradicional y, sobre todo, los foros y blogs de Internet, han transformado radicalmente la naturaleza del crimen, de manera que las víctimas de principio se vieron convertidos en supuestos culpables. No es fácil armonizar ciertos fenómenos de masas anejos a la revolución democrática con el buen sentido, ni se han creado, si es que son concebibles, las instituciones que lo faciliten.

Todo esto ha suscitado, naturalmente, las protestas correspondientes y los llantos oportunos, pero tal vez sea necesario verlo, en cualquier caso, como un último eslabón de la revolución democrática 0 , si se prefiere, de la rebelión de las masas. En todo caso, sin incurrir ni en brindis al Sol ni en jeremiadas más o menos apocalípticas, sería absurdo negarse a ver que la proliferación de toda suerte 
de informaciones, por mucho que sea preferible a la escasez, está dando lugar a nuevos problemas muy similares a los que, en otros órdenes, nos plantean, por ejemplo, los residuos urbanos o el gasto de energía derivado de nuestra movilidad física: problemas que son consecuencia de un determinado tipo de abundancia y de ciertos desajustes que no es sencillo corregir. Es tanto lo que se puede hacer que, pese a esa clase de problemas, seguimos dándole a la máquina de producir teoremas y, por todas partes, la ciencia y la cultura avanzan, aunque quizá no tanto como se nos dice. Pero volvamos a la cuestión que queríamos plantearnos tratando de apartarnos, aunque sea sólo un poco, de unas contradicciones no demasiado estimulantes. Si volvemos por un momento a Aristóteles, o a Newton que a estos efectos sería lo mismo, nos encontramos con que nuestra situación ante el escritorio y ante los documentos es, en relación con la suya, muchísimo más comprometida precisamente porque, a la vez, está increíblemente saturada de posibilidades tecnológicas que aún no sabemos manejar con la debida eficacia en nuestro favor.

De lo que se trata es de saber qué clase de ventajas específicas para el trabajo intelectual podrian derivarse de una situación que las tiene de todo tipo, quizá especialmente en otros terrenos, pero también en éste, aunque, como ya hemos advertido, vengan acompañadas de nuevos problemas que también son homologables con los que aparecen en otros campos de la actividad humana. Dicho de otra manera, la cuestión consiste en averiguar qué cambios positivos se pueden perseguir en una situación general de cambios continuos y aparentemente inevitables. Es necesario pensar en este tipo de cosas porque, al menos hasta la fecha, las preocupaciones de corte científico, cultural e intelectual no han resultado ser las más influyentes en la dinámica de avance general desarrollada desde los comienzos de la era digital.

Empecemos por lo más simple, por los cambios que están afectando a dos elementos básicos del oficio intelectual, la lectura y la escritura. La escritura y la lectura son actividades humanas que, debido a su ejercicio ya inmemorial, nos han hecho olvidar su condición de invento, de tecnologías, simples, pero nada naturales ni espontáneas, como lo prueba el hecho del mucho tiempo que hay que dedicarles en la educación. La invención y el uso de tecnologías siempre modifica de una u otra forma lo que consideramos natural, de modo que si, como es corriente reconocer, la invención de la imprenta tuvo consecuencias de todo orden, las tecnologías digitales traerán consigo una serie de cambios que ahora apenas se están empezando a perfilar.

Vamos a verlo desde el lugar de trabajo del estudioso. La mesa y los medios con que se trabajaba hasta hace realmente poco han dejado paso a un puesto de trabajo típico de la era digital en el que el papel decisivo corre a cargo del ordenador y de sus periféricos. Aunque funcionalmente sirvan para cosas similares, los archivos digitales de texto se parecen poco a los cuadernos de notas en las que los creadores iban apuntando sus ideas incipientes: si hacemos una enumeración de los elementos de que se disponía antes y de los que ahora se dispone tendríamos que llenar una larga lista. Para apreciar mejor algunas diferencias esenciales hagamos una comparación entre los documentos impresos y los textos digitales que son, al tiempo, el finis operis de la escritura y también una condición necesaria para que podemos leer.

Leemos documentos, artículos, libros, y escribimos también documentos, artículos y libros. Las diferencias entre los documentos impresos y sus equivalentes digitales nos van a poner sobre la pista de algo fundamental. Cuando un escritor escribe no lo hace sólo movido por su inspiración sino que tiene a la vista una finalidad muy precisa, a saber, cumplir las especificaciones del tipo de publicación que pretende hacer en cuanto a género, extensión, estilo, estructura, etc. También leemos de la misma manera, sabiendo siempre lo que estamos leyendo, el género a que pertenece, sabiendo claramente quién es el autor de lo que leemos, etc.

Las diferencias esenciales entre un documento impreso y su equivalente digital son ahora unas pocas y decisivas, pero pueden llegar a ser muchas más. Un documento impreso es un texto finito que se caracteriza en el orden bibliotécnico por una serie de descriptores muy bien conocidos. En el orden lógico, el documento tiene una serie de características peculiares, lo que llamaríamos su contenido conceptual, que el lector deberá llegar a dominar si es que comprende realmente lo que el documento dice.

Los documentos impresos son finitos en el sentido de que están cerrados, han de ser leídos de manera secuencial, al menos en principio, y no exhiben más que una serie de rasgos convencionales que permiten situar al texto en una 
determinada tradición, por ejemplo a través de las citas que aduce o a través de su estilo o de las informaciones que el autor ha proporcionado, se supone que de buena $\mathrm{fe}$, en el seno mismo del texto.

Con el equivalente digital de un texto cualquiera se pueden conservar todas las características de la copia impresa y, además, empiezan a aparecer una serie de características completamente nuevas que dotan al lector, y en su caso al escritor, de unas posibilidades inalcanzables para el texto impreso. Aunque la lectura del texto digital sea también ordinariamente secuencial, el hecho de que podamos buscar dentro de él de modo automático le dota de nuevas e interesante propiedades. Pondré un ejemplo simple: supongamos que se trata de analizar el uso de conceptos jurídicos en el Quijote. En un entorno predigital, este trabajo habría supuesto confeccionar unos centenares de fichas que llevarían un tiempo precioso y que podian contener con mucha facilidad errores a la vez inevitables y lamentabilisimos. Cualquiera que haya trabajado de esta manera sabe lo que es la desesperación cuando una ficha se pierde o cuando tiene un dato mal anotado que no se consigue rectificar tras diversos $y$ deprimentes intentos. Parte, desde luego, de ese esfuerzo, podría haberse evitado para emplearlo en objetivos más ambiciosos, de disponer de un buscador de texto como los que ahora tenemos, que permiten precisar con todo rigor, por ejemplo, el número de veces que una determinada expresión aparece en el documento que queremos analizar.

Los textos digitales se pueden considerar, por tanto, como abiertos, puesto que pueden ser recorridos automática-

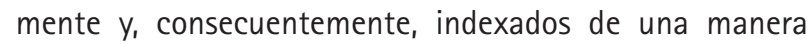
muchísimo más efectiva y rápida que lo que es posible en sus equivalentes impresos. Los textos ya podrian no tener títulos, puesto que ese sistema de identificación de la singularidad de un texto depende de la tecnología de la impresión, es justo aquello que se pone en la tapa del libro para indicar del modo que parezca más conveniente de qué va lo que está tapado por las hojas opacas en las que se imprime el texto. Los textos digitales están, de algún modo al descubierto, pueden ser recorridos de muchas maneras, pueden ocupar muy distintos lugares en una lectura de conjunto y ser vistos en comparaciones que antes eran muy poco corrientes cuando no directamente imposibles. Es muy fácil ver con ellos que ningún texto tiene una única lectura, ni un único tema, de modo tal que cualquier texto podría tener distintos títulos.

Esta nueva clase de cualidades del texto digital nos permitirán saber qué es lo que hay en cada texto e, idealmente, que es lo que hay en todos los textos, puesto que, como se ha sugerido, entre otros por Kevin Kelly, todos los textos son ya un único texto desde el momento en que podrían ser todos abiertos de manera conjunta y recorridos por un buscador. Con sólo pensar que encontrar lo que hay en textos de uno u otro tipo es una parte realmente importante del trabajo de los investigadores se adivina que, por este flanco, nos pueden venir novedades muy sustanciosas.

El acceso y la recuperación de textos digitales resultarán mucho más baratos, sencillos y eficaces que su equivalente en el entorno de las publicaciones impresas. Localizar un texto determinado en un millar de libros impresos puede requerir horas y proporcionar disgustos sin cuento. Hacer lo mismo en el equivalente digital es algo enteramente trivial. La razón de la diferencia está en que la tecnología digital nos proporciona sistemas muchísimo más eficaces de singularizar un texto que el sistema tradicional de impresión. Cualquier texto es único en tanto consiste en una determinada colección de signos con un determinado orden. Nosotros leemos el texto semánticamente, pero los sistemas de búsqueda lo tratan como una mera combinación de signos que tiene unas ciertas propiedades compositivas que la tecnología digital puede detectar con facilidad. Este tipo de propiedades se encuentran, desde luego, en cualquier clase de texto, tanto en un escrito luminoso, elegante e intelectualmente decisivo, como en una colección de letras escritas al azar al pasar un gato por encima de un teclado. Pero la tecnología digital nos permite utilizar semánticamente esas propiedades $y$, al hacerlo, nos proporciona un arma decisiva: podemos determinar la singularidad de cualquier texto con el grado de precisión que queramos y eso nos va a permitir formas de catalogación, localización y uso realmente impensables en el pasado.

Podemos llamar descriptores de singularidad o localizadores a ese casi infinito conjunto de términos o combinaciones de términos que nos permiten localizar y acceder a un documento determinado entre otros muchos similares 0 , en particular, al único documento que posee esa precisa combinación de signos. Gracias a las características del

ARBOR CLXXXV 737 mayo-junio [2009] 541-550 ISSN: 0210-1963

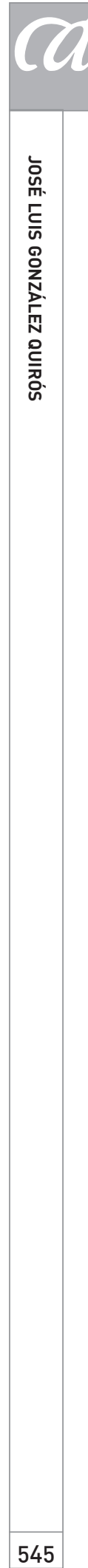


texto digital podremos localizar (como ahora lo hace Google, por ejemplo) un texto específico a partir de algunas palabras o nombres que están presentes en él. En otra ocasión (González Quirós y Gherab Martín, 2006, 177) he aducido un ejemplo muy significativo: ya con muy poca memoria por su avanzada edad, el filósofo Karl R. Popper quería referirse en una conferencia a su The Open Society and Its Ennemies, pero no recordaba el título que le había puesto, aunque sí de qué trataba, de las ideas de Platón y los orígenes del pensamiento autoritario. Pues bien, con esas escasas referencias se puede recuperar hoy en la red el título del libro y buena parte de su contenido y, en un futuro no muy lejano, debería ser posible hacer algo parecido, y con resultados mucho más satisfactorios casi con cualquier documento que haya sido publicado.

De cualquier modo, la singularidad más interesante de un documento es su singularidad intelectual, en el caso de que la tenga, lo que le hace ser original, único, pionero o cualesquiera otra de las propiedades que asignamos a textos valiosos tanto desde el punto de vista científico como literario. Como es lógico, esta clase de textos es mucho menos numerosa que su complementaria, aunque la originalidad sea, desde luego, un carácter, digamos, relativo. Abundan los textos que no se proponen ser originales, sencillamente porque pretenden recoger el estado de una determinada cuestión, por ejemplo, en un momento dado o porque son textos de carácter didáctico. Desde el punto de vista del avance del conocimiento lo que interesa son los textos innovadores, originales, seminales, pero es obvio que las revistas y las bibliotecas están repletas de textos perfectamente prescindibles y que no siempre coinciden con los que, de hecho, nadie utiliza. La tecnología digital nos va a facilitar también la evaluación de las propiedades conceptuales, históricas y lógicas de un texto, y lo que es más importante, de la recepción que ha tenido, mediante lo que hemos definido como "descriptores popperianos" (González Quirós y Gherab Martín, 2006, 168 y ss.). Un descriptor popperiano es un metatexto que interpreta, sitúa y califica a otro texto, de manera que muchos textos, que, además de que tengan perfecto sentido por y valor sí mismos, pueden ser empleados como metatextos descriptores de otro con el que mantengan relaciones interesantes desde el punto de vista lógico.

Un documento cualquiera puede ser descrito de dos formas que son irreductiblemente distintas porque corresponden a la doble serie de caracteres que posee todo texto, sus valores semánticos y las propiedades combinatorias de sus signos, aquellas que permiten su digitalización, su manejo como un número único distinto a cualquier otro. Las primeras están siempre abiertas a discusión, y la recogida y el análisis sistemático de las opiniones que se vierten sobre un texto nos proporcionaría un instrumento de análisis poderosísimo; las segundas permiten fijar y localizar el texto de una vez y para siempre y nos facilitan una multiplicidad de accesos semánticos empleando la tecnología de los buscadores. Descriptores de singularidad o singularizadores y descriptores popperianos están llamados a ser las dos armas principales que permitan una sistematización del conjunto de textos disponible en el entorno digital.

Explicaré brevemente lo que cabe esperar de ambos. Los primeros nos ayudan a localizar un texto del que conocemos alguna característica, o bien, la clase de textos que poseen precisamente esa característica: se trata, sin más, de aprovechar en un texto abierto la capacidad de búsqueda que la tecnología nos proporciona para acercarnos o encontrar lo que buscamos, de manera que operan en un nivel puramente sintáctico que no requiere otra cosa que disponer de un texto y de un buscador. Los descriptores popperianos operarán en un plano distinto, en un nivel semántico, aunque el trabajo con ellos se facilita enormemente gracias a la existencia de buscadores sintácticos. Un descriptor popperiano es, en realidad, cualquier discurso que se pueda considerar relevante sobre algo, con la ventaja de que en el entorno digital, esa clase de descriptores se pueden arracimar sin gran esfuerzo ni excesivo coste. Los descriptores popperianos nos sirven para acercarnos a lo que nos interesa de un texto cuando intentamos aprender lo que dice, a partir de qué lo dice, cómo lo argumenta, qué clase de verdad aporta y qué presunciones previas tira por tierra, esto es, aquello que lo coloca en un determinado lugar de la red objetiva de cuestiones, de teorias, de argumentos, o, por decirlo a la manera de Karl R. Popper, de conjeturas y refutaciones en que consiste propiamente la disciplina o temática de la que trata. Cualquier texto realiza y explota una determinada posibilidad teórica entre las abundantes posibilidades que existen para decir algo consistente en relación con unos supuestos determinados. No hay una manera única de fijar esa significación pero, del mismo modo que diversos satélites nos proporcionan una aproximación muy certera al lugar en el que estamos sobre la tierra utilizando la tecnología GPS, las opiniones 
que se pueden sostener sobre ese texto y las opiniones que ese texto sostiene sobre los temas que trata forman una trama lógica que permite, teóricamente, una caracterización casi inequívoca del mismo. Del mismo modo que la tecnología de Google escoge las páginas web que son más visitadas, la imagen de una red de opiniones nos permite situar los puntos de controversia decisivos por las convergencias entre los dictámenes de lectores, las reflexiones críticas, las citas hechas al texto, un conjunto de etiquetas que se podrán recoger digitalmente con la misma facilidad que se han recogido hasta ahora los descriptores clásicos del universo de las publicaciones impresas.

Una determinada fórmula textual expresa un análisis de la realidad, una idea, y adquiere una determinada identidad por las cuestiones que plantea, la manera en que las trata y las soluciones o respuestas que sugiere, pero también por las controversias que suscita o podría suscitar cuando sea debidamente leída. Toda esa serie de comentarios relativos a un texto de interés pueden servir para etiquetar su forma digital y deberán ser aportadas por sus autores, por sus comentaristas, recensores y críticos $y_{1}$ en último término, por los bibliotecarios que se vayan a ocupar de recoger y analizar los rastros digitales del paso de la obra por el mundo vivo de la creación, la reflexión y la ciencia. Pues bien, eso que, en el plano de las ideas, es una intensa trama de proposiciones en liza, se puede traducir en su forma digital en una trama de textos que se remiten unos a otros, nítidamente distinguibles de cualesquiera otros textos por similares que sean $y_{\text {, de alguna }}$ manera, en una cifra única, distinta de cualquier otra. $Y$ esa identidad numérica de cualquier texto permite que le puedan ser adjuntados sin confusión toda una serie de textos que a él conduzcan o que en él se han enraizado porque, una vez que un texto está perfectamente fijado, nos podemos permitir el lujo de mezclarlo o empaquetarlo con cualesquiera otros.

Para llegar a ello quedan millones de horas de trabajo y de imaginación: no es un asunto de pura tecnología, puesto que en realidad, la tecnología necesaria está ya casi completamente disponible. Cuando todo esto empiece a ser una realidad de perfiles nítidos, se podrá llevar a cabo una lectura crítica y suficiente de cualquier texto de una manera más fácil y más completa, además de que, como ya sucede, el acceso a cualquier obra será más sencillo y barato. Todo serán ventajas que permitan al investigador concentrarse en lo que realmente importa, en aportar alguna novedad que sea digna de interés.

Para quienes profesan una querencia melancólica ante la posible desaparición del libro tal como lo conocemos, convendrá recordar que la lectura de libros impresos seguirá siendo con toda probabilidad el sistema principal para satisfacer la lectura por placer, aunque seguramente variará la manera en que se obtengan los libros, mientras que la lectura digital será el hábito predominante, seguramente lo es ya, en el trabajo intelectual y científico, en la lectura, digamos, profesional (González Quirós, 2006).

Fijémonos ahora en la escritura. El proceso de interacción entre la escritura y las diferentes formas de explotar digitalmente la lectura de un texto será lento, pero, al final el autor tratará de escribir de manera que su texto se integre de la mejor manera posible en ese nuevo universo. Esto ya sucede en el entorno impreso: un autor sabe que, por ejemplo, no debe sobrepasar una cierta cantidad de palabras para no ser ilegible, o sabe que no debe perder el tiempo hablando de cosas que sus lectores conocen perfectamente. Esta clase de reglas de escritura se perfeccionaran y se harán mucho más complejas en el entorno digital, de manera que cabe suponer que las tecnologías digitales nos van a permitir poner ciertos límites a la proliferación de textos cuando se disponga de las instituciones y las herramientas capaces de poner orden, claridad y accesibilidad en el océano de las publicaciones. El hecho de poder acceder con facilidad a cuanto se ha escrito, evitará la tendencia a la repetición, del mismo modo que hará, forzosamente, que el arte del plagio y cualquiera de sus variantes sea mucho más arriesgado y sutil.

El escritor digital podrá ser más ascético por cuanto tendrá la certeza de que será enteramente inútil, además de casi imperdonable, adornarse con cosas ya bien sabidas y a las que cualquiera puede acceder. Cuando Herodoto tenía que hablarnos de los panfilios, los ligures, los sacas o los licios tenía que darnos multitud de detalles, que ahora tendemos a considerar, seguramente con razón, anormalmente inexactos y desproporcionados, algo que ahora nadie tiene que hacer, por ejemplo, si nos habla de los parisinos, salvo que el libro se dedique precisamente a eso. La ascesis necesaria para ponerse límites, para dar a la imprenta sólo lo que pueda considerarse realmente nuevo y relevante depende directamente de la posibilidad 
de que no tenga sentido simular un conocimiento que, 0 no se posee de primera mano, o está ya en posesión de cualquiera de otras muchas maneras. Es claro que, fuera de ese consenso en la autolimitación que debería estar vigente en la ciencia, quedarán quienes escriban por el puro placer de hacerlo, sin sumisión alguna a instancias objetivas ajenas al texto.

Escribir, como leer, es algo que determinadas personas hacen por una de estas dos razones: o motivadas por la necesidad, o seducidas por el placer. En el caso de la escritura, aunque también cuando leemos o releemos, independientemente de la razón por la que escribamos, se supone que pretenderemos alumbrar una novedad; pero la novedad genuina no está al alcance de cualquiera, de manera que quien se pone a escribir ha de pasar por un angosto estrecho con amenazas en ambas orillas; si satisface su necesidad de escribir se arriesga a no acertar con nada realmente nuevo; si se atiene al imperativo de la novedad se arriesga a perecer frente a la hoja en blanco (ahora, frente a la pantalla), a quedar inédito o a ser muy justamente olvidado. El entorno digital proporciona también algunas salidas a este dilema del escritor, tanto para la escritura creativa como para la literatura científica, al romper el curso tradicional de las cosas en el mundo de la imprenta (escribir, editar, valorar, publicar, distribuir) lo que da lugar a formas nuevas de existencia como, por ejemplo, los blogs en el terreno literario o los archivos de e-prints y pre-prints en el campo de la investigación. En particular, este último tipo de archivos facilitan enormemente la comunicación epistolar con los pares, puesto que la dirección de e-mail del autor suele estar al pie de la mayoría de los textos digitales presentes en esa clase de espacios públicos.

Es obvio que hay formas de escritura que no se pueden valorar con esquemas tan simples como los que representan la oposición entre verdadero y falso o la diferencia entre novedad y repetición. Escribir sin ninguna clase de limitaciones es una condición necesaria si se quiere promover y respetar la libertad de pensamiento. Por lo demás, la necesidad de volver una y otra vez sobre los textos esenciales no se va a agotar jamás. Siempre habrá que interpretarlos que traducirlos al nuevo lenguaje, que ponerlos al día para que no pierdan su capacidad de decirnos cosas.

La idea popperiana de Mundo III es una idealización y no tiene sentido empeñarse en evitar que salga cualquiera a la palestra a decir sus verdades, pero tratar seriamente de reducir la literatura científica y ensayística redundante sería una manera de apreciar mejor el legado del pasado, en espacial esa inmensa multitud de obras huérfanas que, como decía Cortázar de ciertos parajes del estrecho de Magallanes, nadie ha visitado nunca, y reservar nuestras energías para producir o encontrar alguna brizna de auténtica novedad. La literatura de divulgación, las introducciones, los panoramas podrian reducirse a una sistemática lista de enlaces, de manera que pudiésemos reservar las energías del escritor y del lector para los argumentos y las novedades importantes cuando las haya, para guardar un sabio y nutritivo silencio en otras muchas ocasiones.

Al final de su Tractatus (Wittgenstein, 1973, punto 7), el filósofo vienés hizo una recomendación muy radical: "Wovon man nicht sprechen kann, darüber muss man schweigen"3; pues bien, esa recomendación puede encontrar un nuevo sentido en el mundo digital, no tanto porque no se "pueda" escribir, sino porque venga a resultar innecesario hacerlo cuando algo está ya suficientemente bien tratado y el entorno digital nos permite localizarlo y acceder a ello con facilidad. Una cierta forma de compensación a esta nueva "limitación", la encontraremos en las nuevas posibilidades de acceso a esas obras injustamente olvidadas, que han quedado involuntariamente estériles por la ineficiencia de los sistemas tradicionales de distribución, por limitaciones del mercado del papel y la tinta, que deberán desaparecer en el mercado digital.

Escribir un texto a la manera popperiana consistirá en mostrarlo como un haz de proposiciones que se enlazan con una red de textos aún más compleja y que el autor ha leído de una manera determinada, escogiendo a su criterio la más adecuada e innovadora entre las muchas formas distintas en que puede ser comprendido un texto; el autor deberá explicar con claridad cuáles son las aportaciones esenciales de su trabajo y exponerlas con la máxima nitidez para hacer posible, en su caso, alguna forma de refutación. El escritor que actúa de este modo es perfectamente consciente de que su texto se funda en unas determinadas lecturas, aunque no únicamente, como es lógico, y que su valor depende de ellas y de las nuevas aportaciones que haga, además de que comprenderá muy fácilmente que a todos conviene una cierta brevedad. 
Cualquier texto con interés puede escucharse, por tanto, como una especie de polifonía y su contenido raramente podrá agotarse con una sola descripción, por más que unas le cuadren más que otras. Si el autor quiere contribuir a precisar el lugar exacto que ocupa su aportación no debería limitarse a indicar una lista de temas o a escribir un abstract más o menos sugerente, sino que habrá de procurar que su texto quede lo más claramente enmarcado en la compleja malla del saber contemporáneo, en las distintas líneas de investigación que ponen a prueba la línea de demarcación entre lo que se sabe bien y lo que está sometido a discusión. Los lectores, los colegas, los críticos, los estudiosos de todo tipo y los bibliotecarios con preparación para entender el texto podrán y deberán producir nuevas descripciones alternativas y perfeccionar los perfiles de la catalogación que consideran más adecuada.

La ascesis que la tecnología digital podría facilitar para escribir de un modo más contenido no es ninguna amenaza; representa, por el contrario, una oportunidad para concentrar el esfuerzo en las cuestiones que realmente merecen la pena. Escribir siempre será una meta que sólo puede alcanzarse con libertad, pero la buena información hará que nuestra inteligencia pueda rendir mejores frutos sin perderse innecesariamente en senderos que ya estarán perfectamente señalizados. Habrá, por otra parte, que llevar a cabo, con muchísima frecuencia, tareas de revisión de textos que se consideran suficientemente bien servidos porque el significado del pasado va cambiando a medida que el tiempo pasa, y nunca cesa de pasar. Habrá, además, una infinidad de tareas de erudición que se podrán llevar a cabo en condiciones casi enteramente ideales.

No hay que temer ninguna muerte del espíritu a manos de la tecnología, ninguna dictadura del sentido, ninguna cristalización definitiva de nada. Lo único que habrá es mejoras continuas, esfuerzos acumulados, visiones de las cosas cada vez más eficaces. Aunque pensar así, pueda considerarse pecado de optimismo, no deberíamos de olvidar que, en cualquier caso, las tecnologías digitales han acudido, un tanto inesperadamente, eso sí, en nuestro auxilio, en un momento en el que la amenaza del volumen de los archivos impresos había empezado a ser realmente tremenda. La facilidad de manejo de esa clase de volúmenes que nos proporciona el nuevo entorno digital me parece enteramente fuera de discusión, aunque en esta clase de temas abunden todavía los snobs que pretenden alzarse sobre los demás aduciendo una docta ignorantia enteramente fuera de lugar.

El entorno digital no nos facilita solamente un nuevo escritorio, nos va a permitir también una cierta clarificación del mercado del saber, al hacerlo más accesible, más transparente, más capilar y ambicioso, algo más democrático también. Subsistirá, naturalmente, el peer review, pero seguramente adoptará formas muy distintas a las que hoy son habituales, más ágiles, menos escolásticas y orientadas al triage, más abiertas y plurales. Está claro que aquí se van a poner en juego una serie de intereses no siempre tan legítimos como a primera vista pudieran parecer, y que, siendo cierto que hay que mantener el respeto correspondiente a los colegios invisibles, a la academia y a sus instituciones, se podrán habilitar formas que permitan la fertilización del saber que siempre requerirá la presencia de espíritus heterodoxos y burlones como el de Richard P. Feynman (1999, 149): "eso es la ciencia: el resultado del descubrimiento de que vale la pena volver a comprobar por nueva experiencia directa y no confiar necesariamente en la experiencia del pasado. Así lo veo. Ésta es mi mejor definición".

Nunca ha sido fácil ser Aristóteles y ahora es más difícil que nunca, pero deberíamos tratar de que nuestro trabajo, cada vez más difícil por lo mucho que hay que aprender para poder aportar la más mínima novedad, se beneficie de las maravillosas posibilidades de nuestro escritorio. Nuestros trabajos podrán mejorar con una nueva erudición, con la disponibilidad inmediata de fuentes perfectamente organizadas, con la posibilidad de acceder más fácilmente a mercados más amplios y eficientes, con la presencia de sistemas de evaluación más ágiles y abiertos, y esa nueva eficacia en la lectura, en la composición, en evaluación, en la distribución y en el manejo de la riqueza documental puede llegar a ser, si hacemos bien las cosas, el trampolín de formas más complejas y fiables de humanismo y de erudición. 
NOTAS

1 Este artículo ha sido elaborado en el marco del proyecto de investigación HUM2005-02105/FISO, financiado por el Ministerio de Educación y Ciencia.

2 Este artículo está sujeto a la licencia Creative Commons ReconocimientoCompartir bajo la misma licencia 3.0 España (http://creativecommons.org/ licenses/by-sa/3.0/es/).

3 "De lo que no se puede hablar, mejor es callarse".

\section{BIBLIOGRAFÍA}

Feynman, Richard P. (1999): El placer de descubrir, Barcelona, Crítica.

Recibido: 22 de octubre de 2007

Aceptado: 18 de diciembre de 2007

González Quirós, José Luis (2006): "Formas de lectura en el mundo digital", $E l$
Noticiero de las Ideas, 28, X-XII 2006, pp. 35-42.

González Quirós, José Luis y Gherab Martín, Karim (2006): El templo del saber. Hacia la biblioteca digital universal, Barcelona, Deusto y Fundación DMR.

Keen, Andrew (2007): The Cult of the Amateur, New York, Doubleday.

Ortega y Gasset, José (1962): La rebelión de las masas, en Obras completas, II, Madrid, Revista de Occidente.

Surowiecki, James (2004): The Wisdom of Crowds: Why the Many Are Smarter than the Few, and How Collective Wisdom Shapes Business, Economies, Societies, and Nations, New York, Doubleday.

Ulam, Stanislaw M. (1976): Adventures of a Mathematician, New York, Charles Scribner's Sons.
Wittgenstein, Ludwig (1973): Tractatus Logico-Philosophicus, Madrid, Alianza. 